\title{
Effect of Hypotension on Levels of Antidiuretic Hormone in Plasma in Dogs*
}

\author{
ToshIo MURASE AND SHo YOSHIDA \\ The Third Department of Internal Medicine, Faculty of Medicine, \\ University of Tokyo, Tokyo
}

\begin{abstract}
Synopsis
Effect of hypotension on levels of antidiuretic hormone (ADH) in plasma was investigated in dogs. Mild-to-severe hypotension was induced either by intravenous administration of sodium nitroprusside or by hemorrhage. ADH titers in plasma were measured before and after the induction of hypotension. Marked rises of the concentrations of $\mathrm{ADH}$ in plasma were observed following a fall of arterial blood pressure. The physiological meanings of these rises were discussed.
\end{abstract}

It is well known that hemorrhage is a potent stimulus in the release of $\mathrm{ADH}$ (Weinstein et al., 1960; Saito et al., 1969). As for the increased release of ADH following hemorrhage, emphasis is mostly placed on the role of changes in blood volume, but, in a severe blood loss, the release may be influenced by a resultant fall of arterial blood pressure (Gauer and Henry, 1963). Share (1967) suggested that arterial baroreceptors play an important role in the secretion of ADH. The purpose of the present study is to observe an effect of hypotension without reduction of blood volume on levels of $\mathrm{ADH}$ in plasma. Arterial blood pressure was reduced by intravenous administration of sodium nitroprusside. Timed blood samples were collected via a femoral artery and concentrations of ADH in plasma were determined. Experiments of hemorrhagic hypotension were undertaken in order to compare the responses with those of hypotension induced by sodium nitroprusside infusion.

Received for publication April 13, 1971.

* This work was supported in part by Research Grand AM-11278 from NIH, USPHS.

\section{Materials and Methods}

Mongrel dogs of both sexes weighing between 6.0 and $15.4 \mathrm{~kg}$. were used. The dogs were anesthetized by intravenous injection of $30 \mathrm{mg} / \mathrm{kg}$ body weight of pentobarbital sodium and heparinized with 5000 units of heparin sodium. Arterial phasic and mean blood pressure were recorded simultaneously from one femoral artery by using electric manometer with electric averaging circuits. Heart rates and pulse pressure were calculated from the recording chart of arterial phasic pressure. Another femoral artery was cannulated for blood collection and bleeding. Both antecubital veins also cannulated, one for the infusion of sodium nitroprusside or saline solution, and the other for the retransfusion of shed blood and blood replacement. In order to minimize the effect of surgical stress on the secretion of $\mathrm{ADH}$, the experiments were started 30 min after completion of operation. The following three series of experiments were performed.

Experiments of nitroprusside hypotension: Hypotension was induced by intravenous administration of sodium nitroprusside. Sodium nitroprusside of 300 $\mu \mathrm{g} / \mathrm{m} l$ were infused at a rate of $13.8-41.7 \mu \mathrm{g} / \mathrm{kg} / \mathrm{min}$ over $0.9-3.0 \mathrm{~min}$. Infusion dosage was an average of $35.2 \mu \mathrm{g} / \mathrm{kg}$ body weight.

Experiments of hemorrhagic hypotension: The animals were bled from a femoral artery at a speed of 6.7-14.7 $\mathrm{m} l / \mathrm{kg} / \mathrm{min}$ for $1.6-3.8 \mathrm{~min}$ until a mean arterial blood pressure fell to the same order of magnitude that induced by sodium nitroprusside 
infusion. Then the shed blood was returned immediately via an antecubital vein within $4 \mathrm{~min}$.

Control experiments: Physiological saline solution was infused intravenously at a rate of either 0.555 or $0.888 \mathrm{ml} / \mathrm{min}$ over $3 \mathrm{~min}$.

The numbers of dogs used in these three series of experiments were 8,8 and 6 respectively. In all of the experiments, arterial blood were collected at four minutes intervals after the stop of infusion or hemorrhage. In these experiments, arterial blood was used for the determination of $\mathrm{ADH}$ in order to simplify the experimental procedure. Besides, the levels of $\mathrm{ADH}$ in arterial blood are physiologically more meaningful than those in the jugular vein blood. Each blood sample was drawn over a period of $40 \mathrm{sec}$ and was approximately $35 \mathrm{ml}$ in volume. During the collection of arterial blood, almost the same amounts of dog blood was transfused via a cannulated antecubital vein in order to minimize the influence of blood collection upon ADH secretion. Plasma ADH was extracted and concentrated according to the method of Yoshida et al. (1963) and ADH concentrations were determined by bioassay in the water loaded, ethanolanesthetized rats. The recovery of $\mathrm{ADH}$ during the periods of these experiments was $56.0 \pm 3.2 \%$ (mean $\pm \mathrm{SE})(\mathrm{n}=12)$. Plasma ADH titers were not corrected according to recovery rate. The statistical significance of differences in the fall of mean arterial blood pressure and in $\mathrm{ADH}$ concentrations in plasma between the two groups were evaluated by Student's t-test. The paired analysis was applied to evaluate changes in mean arterial blood pressure and plasma $\mathrm{ADH}$ titers in the group.

\section{Results}

Pressure changes: Mean arterial blood pressure prior to experiments was an average of $99.9 \pm 3.1 \mathrm{~mm} \mathrm{Hg}$ and no significant differences were seen among these three groups of dogs. In the experiments of sodium nitroprusside infusion, mean arterial blood pressure fell promptly to $51.0 \pm 7.3 \%$ (mean $\pm \mathrm{SE}$ ) of initial level when the infusion was discontinued and, within $30 \mathrm{sec}$ after the stop of infusion, it reached to the minimum level of $41.5 \pm 5.6 \%$ (Fig. 1). But soon after, mean arterial blood pressure began to rise rapidly. Four minutes later it rose to $93.1 \pm 4.5 \%$ of the control value and then sustained about the same level. Heart rates were recorded in four dogs.

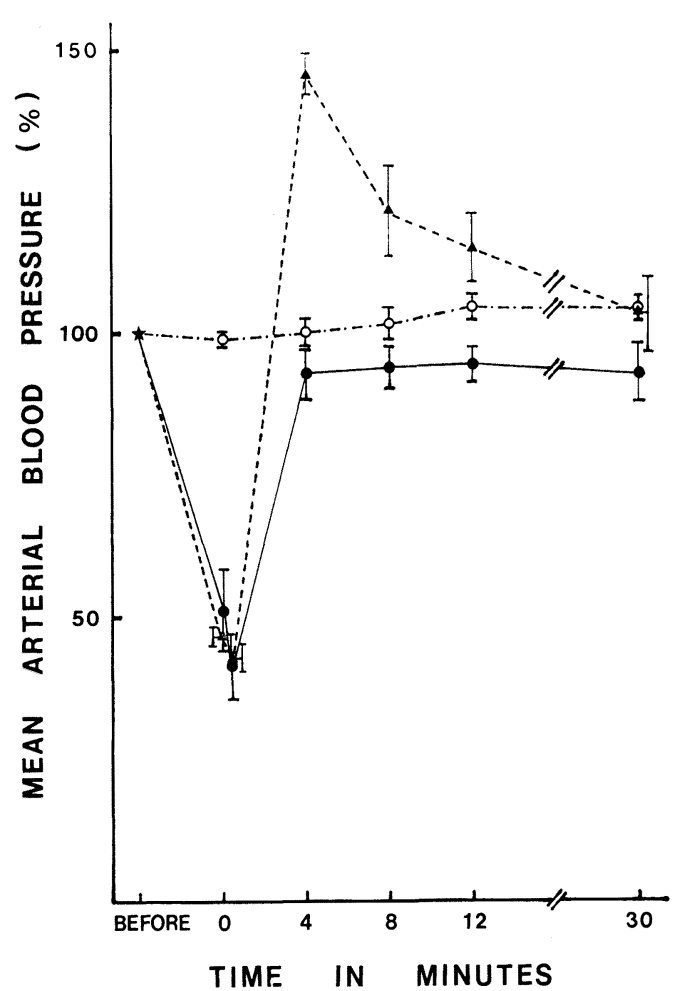

Fig. 1. Effect of hypotension induced by the infusion of sodium nitroprusside solution (-), hemorrhagic hypotension $\left(\mathbf{A}_{---\mathbf{A}}\right)$ and saline infusion $(\bigcirc-\cdot-\bigcirc)$ on the changes in mean arterial blood pressure of the femoral artery in dogs. The time at $0 \mathrm{~min}$ is the point at which the infusion or hemorrhage was stopped. The vertical bars indicate the standard error of the mean.

Considerable increases were observed during the infusion in three of the animals, but no change in one. Pulse pressure was recorded in six dogs. It decreased by an average of $15 \%$ of the preexperimental value at the time when the infusion was stopped, $29 \%$ after four minutes and thereafter increased gradually. In the experiments of hemorrhagic hypotension, mean arterial blood pressure also fell rapidly to $46.6 \pm 1.4 \%$ of initial level with concomitant fall of $40 \%$ of pulse pressure and it reached to the minimum level of $42.9 \pm$ $2.8 \%$ within 30 seconds after stop of bleeding. Rapid retransfusion of the shed blood into 
hemorrhaged dogs was followed by a marked elevation of mean arterial blood pressure and, four minutes later, it increased by an average of $46 \%$ over pre-hemorrhage levels. Pulse pressure recovered to $95 \%$ of initial value. Heart rates increased in five of the animals and decreased in three. Between these two groups of experiments, there were no significant differences in the magnitude of a fall of mean arterial blood pressure. Mean arterial blood pressure, pulse pressure and heart rates remained relatively constant in the control experiments.

$A D H$ changes: Hypotension induced by infusion of sodium nitroprusside resulted in an increase in plasma $\mathrm{ADH}$ titers from $18.6 \pm 4.7$ to $52.7 \pm 8.7 \mu \mathrm{U} / \mathrm{ml}$ (Fig. 2). These rises were statistically highly significant ( $p<0.005$ ). The increment of plasma ADH titers did not correlate with total doses of sodium nitroprusside infused $(r=0.02)$ or doses infused per $\mathrm{kg}$ body weight $(\mathrm{r}=-0.14)$. There were also no correlation between the increment of plasma ADH titers and the fall of mean arterial blood pressure at the stop of infusion $(r=0.299)$ and at the point mean arterial blood pressure fell maximumly $(r=0.21)$. Four min later, when mean arterial blood pressure recovered, the elevated plasma ADH titers decreased significantly to $27.2 \pm 9.6 \mu \mathrm{U} / \mathrm{m} l(\mathrm{p}<0.02)$. But, $12 \mathrm{~min}$ later, striking rises of plasma $\mathrm{ADH}$ concentrations were observed in six of the eight $\operatorname{dogs}(299 \pm 121 \mu \mathrm{U} / \mathrm{m} l)$. The rises were very variable in amounts, and so those were statistically not significant $(0.05<\mathrm{p}<0.1)$. In the experiments of hemorrhagic hypotension, blood loss of $25.4 \pm 2.0 \mathrm{ml} / \mathrm{kg}$ body weight caused significant increase in plasma $\mathrm{ADH}$ concentrations fiom $19.4 \pm 7.9$ to $110.3 \pm 37.7 \mu \mathrm{U} / \mathrm{m} l(\mathrm{p}<0.05)$. After $4 \mathrm{~min}$, it fell significantly to $36.8 \pm 8.5 \mu \mathrm{U} / \mathrm{m} l$ $(\mathrm{p}<0.05)$ and thereafter progressively returned to the control level. There were little changes in the concentrations of plasma ADH in the control experiments. Plasma $\mathrm{ADH}$ titers after hypotension and hemorrhage were

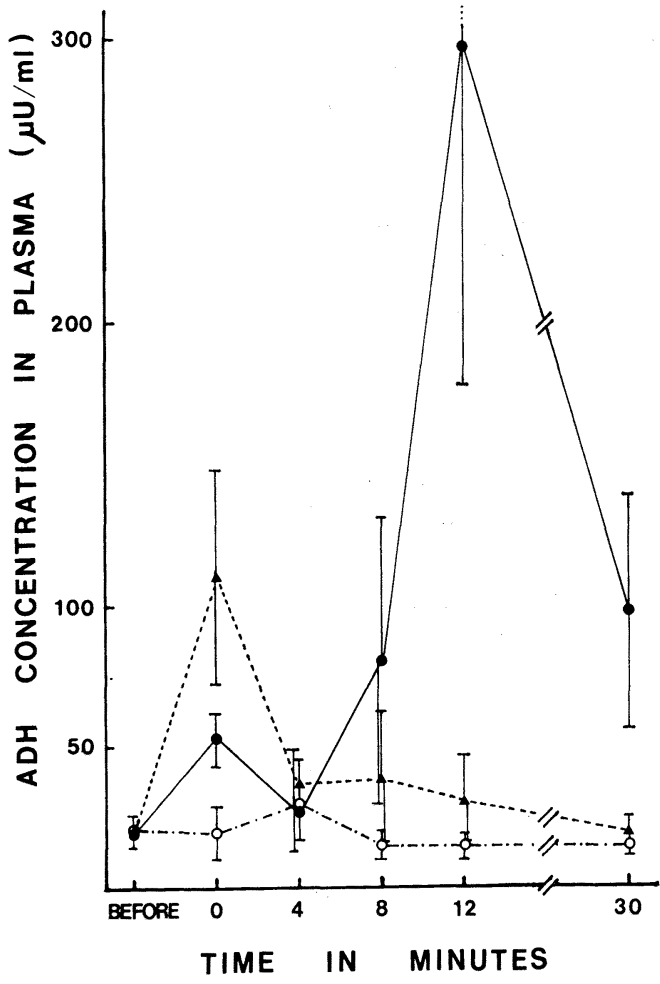

Fig. 2. Effect of hypotension induced by the infusion of sodium nitroprusside solution (-) hemorrhagic hypotension ( $\left.\boldsymbol{\Delta}_{---\boldsymbol{\Delta}}\right)$ and saline infusion $(\mathrm{O}--\mathrm{O})$ on the concentration of $\mathrm{ADH}$ in arterial blood plasma in dogs. The time at 0 min is the point at which the infusion or hemorrhage was stopped. The vertical bars indicate the standard error of the mean.

both significantly higher than those in the corresponding blood samples of the control experiments. The increment of ADH titers in plasma in response to hemorrhagic hypotension seemed to be at a somewhat higher than those in response to hypotension induced by sodium nitroprusside infusion, but there was no statistical significance between two groups of experiments. $(0.1<\mathrm{p}<0.2)$.

\section{Discussion}

The results of the present experiments show that a moderate-to-servere hypotension with- 
out reduction of blood volume caused marked increases of ADH levels in plasma. The elevation of the concentrations of $\mathrm{ADH}$ in plasma following infusion of sodium nitroprusside was biphasic, whereas single peak was observed after hemorrhagic hypotension (Fig. 2). The first peak of the rises of plasma ADH concentrations which appeared immediately after hypotension induced by infusion of sodium nitroprusside corresponded to the rise of those observed in dogs with hemorrhagic hypotension and it appeared that a fall of arterial blood pressure caused increases in $\mathrm{ADH}$ titers in plasma. Following this first peak, remarkable rises of concentrations of $\mathrm{ADH}$ in plasma were observed unexpectedly in six of the eight animals infused with solution of sodium nitroprusside. Compared with the results of hemorrhage experiments, it cannot be considered that these rises occurred as a delayed response to hypotension. It was reported that sodium nitroprusside may act directly on vascular smooth muscle and depresses blood pressure (Page et al., 1955). It decomposes gradually in the blood with liberation of cyanogen which inhibits cell respiration. Although there is no direct evidence relevant to this point, massive amounts of $\mathrm{ADH}$ release may be stimulated by sodium nitroprusside itself and/or by its metabolites.

In dogs infused with solution of sodium nitroprusside, a fall of arterial blood pressure without any changes in blood volume and probably in plasma osmolality, produced an average four-fold increase in the concentrations of $\mathrm{ADH}$ in plasma. Four min later when arterial blood pressure returned almost to the control level, plasma ADH titers decreased significantly. The increment of plasma $\mathrm{ADH}$ concentrations in response to hemorrhagic hypotension seemed to be at a somewhat higher than those in response to hypotension induced by sodium nitroprusside infusion and this tendency could possibly be explained by that, besides hypotensive effect, reduction of blood volume additively influ- enced the levels of ADH in plasma in hemorrhage experiments. The mechanism of the rises of ADH levels in plasma after hypotension induced either by the administration of sodium nitroprusside or by hemorrhage is not clarified in these experiments. This may be the results of increased release of $\mathrm{ADH}$ from neurohypophysis or decreased inactivation of ADH.

The increased amounts of ADH observed in our experiments may have some physiological meanings. Those may alter the distribution of blood volume to be advantageous to the circulatory function. Small doses of vasopressin which do not raise blood pressure are reported to cause the decrease of the blood flow in the peripheral circulation (Takacs and Albert, 1963). Frieden and Keller (1954) reported that the dogs with diabetes insipidus are more sensitive to the hypotensive effects of hemorrhage than normal animals and that administration of aqueous pitressin in the dogs increases resistance to hemorrhage. Besides, Rocha e Silva and Rosenberg (1969) demonstrated that infusion of pitressin which maintains the blood level of ADH at $50 \mu \mathrm{U} /$ $\mathrm{m} l$ can cause a rise in blood pressure by over $20 \mathrm{~mm} \mathrm{Hg}$ in vagotomized carotid sinus denervated hypophysectomized dogs. Considering from these reports, marked rises of the concentrations of ADH in plasma following hypotension may play an important role in preventing arterial blood pressure from falling into the shock levels.

\section{Acknowledgement}

The authors wish to express our gratitude to Professor Kiku Nakao, Dr. Hiroshi Ibayashi and Dr. Toshikazu Saito for their valuable advices.

\section{References}

Frieden, J. and A. D. Keller (1954). Circulation Research 11, 214. 
Gauer, O. H. and J. P. Henry (1963). Physiol. Rev. 43, 423.

Page, I. H., A. C. Corcoran, H. P. Dustan and T. Kappanyi (1955). Circulation 11, 188.

Rocha e Silva, M. Jr. and M. Rosenberg (1969). J. Physiol. 202, 535.

Saito, T., S. Yoshida and K. Nakao (1969). Endocrinology 85, 72.
Share, L. (1967). Endocrinology 81, 1140. Takacs, T. and K. Albert (1963). Experimentia 19, 365.

Weinstein, H., R. M. Berne and H. Sachs (1960). Endocrinology 66, 712.

Yoshida, S., K. Motohashi, H. Ibayashi and S. Okinaka (1963). J. Lab. Clin. Med./62, 279. 